\title{
Histomorfometria Óssea de Ratas Hipertireóideas Lactantes e Não-Lactantes
}

\begin{abstract}
RESUMO
O objetivo deste estudo foi verificar se o hipertireoidismo potencializa a osteopenia causada pela lactação. Foram utilizadas 24 ratas adultas distribuídas em quatro grupos: eutireóideo não lactante (controle), eutireóideo lactante, hipertireóideo não-lactante e hipertireóideo lactante. Todos os animais foram necropsiados, 20 dias após a gestação. As vértebras torácicas e lombares, 0 fêmur e a tíbia foram colhidos, descalcificados e submetidos à análise histomorfométrica. O grupo eutireóideo lactante apresentou osteopenia intensa em todos os sítios ósseos estudados. No grupo hipertireóideo não-lactante, não houve alteração da porcentagem de tecido ósseo trabecular nos sítios analisados. No grupo hipertireóideo lactante, havia osteopenia na tíbia e no fêmur, semelhante à do grupo eutireóideo lactante. Mas a porcentagem de tecido ósseo trabecular em todos os corpos vertebrais foi significativamente maior em comparação ao grupo eutireóideo lactante. Conclui-se que o hipertireoidismo não agrava a osteopenia lactacional em ratas, mas minimiza a osteopenia vertebral por estimular a atividade osteoblástica. (Arq Bras Endocrinol Metab 2008; 52/4:677-683)
\end{abstract}

Descritores: Osso; Osteopenia; Lactação; Hipertireoidismo; Rata.

\section{artigo original}

\author{
ROGÉRIA SERAKIDES \\ Natália de Melo Ocarino \\ FERNANDA DO Carmo MagalHäES \\ Cíntia de Almeida Souza \\ EVELINE DIAS LEITE \\ EdMILSON SANTOS de Freitas
}

Setor de Patologia do

Departamento de Clínica e Cirurgia Veterinárias da Universidade Federal de Minas Gerais (UFMG), Belo Horizonte, $M G$, Brasil. 


\section{INTRODUÇÃO}

A GESTAÇÃO E A LACTAÇÃO caracterizam-se por alterações significativas do perfil endócrino materno, particularmente dos níveis de estrógeno e prolactina, que, entre seus inúmeros efeitos, atuam também no tecido ósseo $(1,2)$. Enquanto na gestação há elevados níveis de estrógeno, na lactação há hipoestrogenismo e hiperprolactinemia (3), que podem estar envolvidos na gênese da osteopenia lactacional. Além disso, durante a gestação e a lactação, há transferência de cálcio da mãe para o feto e hipercalciúria (4), o que causa na mãe desequilíbrio entre reabsorção e aposição ósseas, balanço negativo de cálcio sérico (5) e osteoporose lactacional (3). Assim, gestações sucessivas sem recuperação da massa óssea podem ter impacto negativo futuro sobre o tecido ósseo, aumentando o risco de osteoporose durante o período reprodutivo ou na menopausa (4). Além disso, deficiências de cálcio, vitaminas e alterações endócrinas podem alterar o metabolismo ósseo, agravando a osteopenia lactacional (6).

Já foi estudado o efeito do hipertireoidismo associado à osteopenia pós-castração em modelos animais $(7,8)$ e em associação à osteopenia pós-menopausa $(9,10)$. Os resultados destes estudos permitiram concluir que o hipertireoidismo deve ser considerado fator de risco para a osteoporose causada pela deficiência dos hormônios sexuais $(9,10)$, e que os efeitos da administração de tiroxina são dose e tempo dependentes, variando entre os diferentes sítios do esqueleto (8). Mas a literatura carece de informações sobre o efeito da associação hipertireoidismo-lactação no tecido ósseo.

O objetivo deste estudo foi comparar a histomorfometria óssea de ratas lactantes tratadas ou não-tratadas com tiroxina, a fim de verificar se o hipertireoidismo constitui fator de risco para a osteopenia lactacional.

\section{MATERIAL E MÉTODOS}

Foram utilizadas 24 ratas Wistar com dois meses de idade (adultas), alojadas em caixas plásticas (quatro a cinco ratas/caixa) e recebendo ração comercial ( $1,4 \%$ de cálcio, $0,60 \%$ de fósforo e $22 \%$ de proteína) e água ad libitum. As ratas foram mantidas em regime de 12 horas de luz e 12 horas de escuro, à temperatura de $25^{\circ} \mathrm{C}$. Após o período de sete dias de adaptação, os animais foram divididos em quatro grupos experimentais: eutireóideo não-lactante (controle) $(\mathrm{n}=6)$, eutireóideo lactante $(\mathrm{n}=6)$, hipertireóideo lactante $(\mathrm{n}=6)$ e hipertireóideo não-lactante $(\mathrm{n}=6)$.

Os animais dos grupos hipertireóideo receberam tiroxina (L-thyroxine, Sigma, Sant Louis, USA-T2376) na água de beber, na concentração de $1,6 \mu \mathrm{g} / \mathrm{ml}$, durante a indução, e de $0,8 \mu \mathrm{g} / \mathrm{ml}$, durante a gestação e a lactação. Os animais dos grupos eutireóideos receberam apenas água, como placebo.

A partir do consumo diário médio de água ingerido por animal, estimou-se que a dose diária de tiroxina ingerida por animal foi de $60,43 \mu \mathrm{g} \pm 8,82$, durante a indução (dois meses) e de $39,72 \mu \mathrm{g} \pm 8,85$, durante a gestação e a lactação.

Após dois meses do início do tratamento com tiroxina, as ratas dos grupos hipertireóideo e eutireóideo lactantes eram colocadas com ratos machos adultos, na proporção de quatro fêmeas para cada macho, durante a noite por período de 12 horas. Após o acasalamento, pela manhã, era realizada citologia vaginal nas ratas que estavam com os machos. A cópula era confirmada pela presença de espermatozóides no esfregaço vaginal, e este dia era designado como dia zero. As fêmeas que não apresentaram espermatozóides na citologia vaginal eram colocadas novamente com machos na noite seguinte, até que se encontrassem espermatozóides na citologia vaginal (11).

A partir dos 19 dias de gestação até o momento da eutanásia, cada fêmea gestante era isolada em caixa plástica. Elas permaneceram com os filhotes até o desmame, ou seja, 20 dias após a gestação, quando todos os animais foram necropsiados.

A eutanásia foi realizada por punção cardíaca precedida por anestesia intraperitoneal com pentobarbital 2,5\% (30 mg/kg), de acordo com procedimento aprovado pelo Comitê de Ética em Experimentação Animal da Universidade Federal de Minas Gerais (UFMG).

À necropsia, as carcaças foram seccionadas em duas metades, pelo seu eixo longitudinal. Após pré-fixação em formalina a 10\%, neutra e tamponada, por 96 horas, de uma hemiparte da carcaça, foi dissecado o fêmur, a tíbia e as vértebras torácicas (torácicas 1-7 e 8-13) e lombares (1-3 e 4-6) para posterior descalcificação. A descalcificação foi realizada em EDTA a 10\%. Após completa descalcificação controlada por raios $\mathrm{X}$, todos os segmentos vertebrais e os ossos longos foram seccionados longitudinalmente. Em seguida, os ossos foram processados pela técnica de inclusão em parafina, as secções histológicas foram cortadas a $4 \mu \mathrm{m}$ e coradas pela 
técnica da hematoxilina-eosina para avaliação histomorfométrica.

Para a determinação da quantidade de osso trabecular, foi realizada morfometria em secções histológicas do fềmur, da tíbia e das vértebras. No osso longo, numa área tecidual média de $8 \mathrm{~mm}^{2}$, iniciada a $1 \mathrm{~mm}$ abaixo da placa epifisária e da cartilagem articular foram determinados, com objetiva de $40 \times$, as porcentagens de osso trabecular com o auxílio de uma ocular micrométrica, contendo uma gratícula com 25 pontos. As variáveis foram determinadas em total de $10 \mathrm{cam}$ pos na região da epífise e 10 campos na metáfise, totalizando 250 pontos cada. Nos segmentos vertebrais, com objetiva de $40 \times$, as mesmas variáveis foram determinadas em total de 9 campos/vértebra, sendo 3 campos iniciados a $1 \mathrm{~mm}$ abaixo de cada placa epifisária e os três campos restantes, tomados na região média do corpo vertebral, totalizando, assim, 225 pontos por vértebra (12).

O hipertireoidismo foi confirmado pela dosagem das concentrações plasmáticas de T4 total nos animais dos grupos eutireóideo e hipertireóideo não-lactantes. A dosagem foi realizada pela técnica da quimioluminescência (Access Immunoassay System, Sanofi Diagnostics Pasteur Inc., Chaska, MN, EUA) em sistema totalmente automático e de acordo com as recomendações do fabricante dos kits. Os coeficientes de variação intra e inter-ensaios foram de $4 \%$ e $7 \%$, respectivamente.

O delineamento utilizado foi inteiramente ao acaso. Para cada variável, a média e o desvio-padrão foram determinados. Os dados foram submetidos à análise de variância ANOVA do programa estatístico Instat (Graph Pad Software, Versão 3.00, 32 Win 95/NT, Created December 23 1997) e as médias foram comparadas pelo teste Student-Newman Keuls (SNK).

\section{RESULTADOS}

Os níveis plasmáticos de tiroxina nos grupos tratados com tiroxina foram significativamente mais elevados em comparação ao grupo não-tratado, confirmando o estado hipertireóideo destes animais (Tabela 1). Além disso, as ratas tratadas com tiroxina apresentavam comportamento agressivo, polifagia e poliúria, alterações compatíveis com o hipertireoidismo.
Tabela 1. Média e desvio-padrão da concentração plasmática de T4 total $(\mu \mathrm{g} / \mathrm{dl})$ nas ratas tratadas ou não com tiroxina.

\begin{tabular}{lc}
\hline Grupo & Concentração de T4 total $(\boldsymbol{\mu g} / \mathrm{dl})$ \\
\hline Não-tratadas & $3,33 \pm 0,71 \mathrm{~b}$ \\
\hline Tratadas & $4,7 \pm 0,36 \mathrm{a}$ \\
\hline
\end{tabular}

*Médias com letras minúsculas iguais na coluna não diferem entre si $(p \geq 0,05)$.

No grupo eutireóideo não-lactante (controle), as trabéculas epifisárias e metafisárias dos ossos longos e vértebras apresentavam-se em grande quantidade, espessas e confluentes (Figura 1A). A cobertura osteoblástica era formada por células cuboidais com núcleos grandes ou por células fusiformes. Os osteócitos mostravam-se ora ativos, com núcleos grandes alojados em lacunas periosteociticas alargadas, ora inativos com núcleos pequenos alojados em lacunas estreitas e pouco basofílicas.

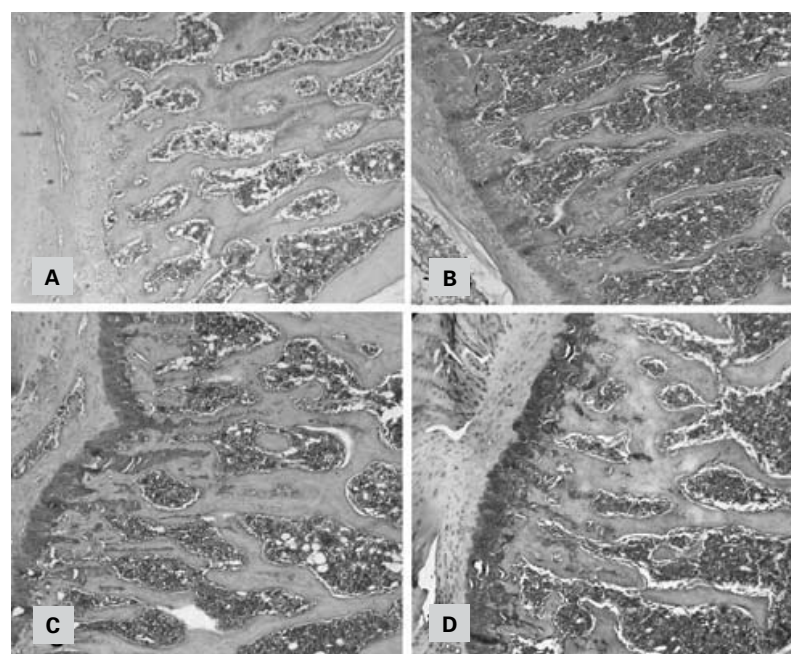

Figura 1. Vértebras torácicas 8-13 de ratas, HE, 143x. A) grupo eutireóideo não-lactante com trabéculas espessas e conectadas; B) grupo eutireóideo lactante com trabéculas finas e desconectadas; C) grupo hipertireóideo não-lactante semelhante ao controle; D) grupo hipertireóideo lactante com trabéculas coalescentes e mais espessas que as do grupo eutireóideo lactante. 
No grupo eutireóideo lactante, as alterações osteopênicas observadas foram acentuadas em todos os sítios analisados quando comparado ao grupo-controle (Tabela 2). A porcentagem de trabéculas epifisárias e metafisárias dos ossos longos e vértebras era significativamente menor comparada ao controle. As trabéculas eram delgadas, desconectadas e fragmentadas (Figura 1B). A maioria dos osteócitos apresentava núcleos grandes alojados em lacunas periosteocíticas alargadas com bordas basofílicas, característica compatível com o aumento da reabsorção óssea por osteólise osteocítica. A cobertura osteoblástica era reduzida com a presença de osteoblastos fusiformes (inativos). A cortical também se apresentou delgada e recoberta por periósteo pouco celularizado e delgado.
No grupo hipertireóideo não-lactante, a porcentagem de tecido ósseo trabecular não diferiu do grupo controle em nenhum dos sítios analisados (Tabela 2). Neste grupo as trabéculas ósseas apresentavam-se espessas e confluentes (Figura 1C) semelhantes ao grupocontrole. A cobertura osteoblástica era constituída por células cuboidais e com núcleo volumoso (ativas). Havia focos ocasionais de hiperplasia osteoblástica e acúmulo de osteóide. Os osteócitos mostravam-se ora ativos, com núcleos grandes alojados em lacunas periosteocíticas alargadas e ora inativos com núcleos pequenos alojados em lacunas estreitas e pouco basofilicas.

No grupo hipertireóideo lactante, havia osteopenia menos acentuada quando comparada ao grupo eutireóideo lactante nas vértebras torácicas e lombares (Tabela 2).

Tabela 2. Média e desvio-padrão da porcentagem de osso trabecular nos ossos longos e vértebras de ratas adultas eutireóideas e hipertireóideas lactantes e não-lactantes.

\begin{tabular}{|c|c|c|c|c|}
\hline \multirow[t]{2}{*}{ Sítio ósseo } & \multicolumn{4}{|c|}{ Grupo } \\
\hline & $\begin{array}{c}\text { Eutireóideo } \\
\text { não-lactante } \\
\text { (controle) }(n=6)\end{array}$ & $\begin{array}{l}\text { Eutireóideo lactante } \\
\qquad(n=6)\end{array}$ & $\begin{array}{l}\text { Hipertireóideo } \\
\text { não-lactante } \\
(n=6)\end{array}$ & $\begin{array}{l}\text { Hipertireóideo } \\
\text { lactante } \\
(n=6)\end{array}$ \\
\hline Tíbia & $60,66 \pm 8,63 \mathrm{~A}$ & $24,26 \pm 10,95 B$ & $55,12 \pm 11,34 \mathrm{~A}$ & $29,07 \pm 7,08 \mathrm{~B}$ \\
\hline Fêmur & $61,82 \pm 9,66 \mathrm{~A}$ & $32,22 \pm 10,86 B$ & $55,22 \pm 7,14 \mathrm{~A}$ & $33,75 \pm 6,73 B$ \\
\hline Vértebras torácicas 1-7 & $60,68 \pm 7,23 \mathrm{~A}$ & $29,68 \pm 5,31 C$ & $62,22 \pm 4,20 \mathrm{~A}$ & $49,87 \pm 7,54 \mathrm{~B}$ \\
\hline Vértebras torácicas 8-13 & $60,32 \pm 3,37 \mathrm{~A}$ & $30,36 \pm 3,58 \mathrm{C}$ & $57,54 \pm 2,27 \mathrm{~A}$ & $48,42 \pm 4,13 B$ \\
\hline Vértebras lombares 1-3 & $53,98 \pm 1,94 \mathrm{~A}$ & $32,08 \pm 3,46 C$ & $55,86 \pm 2,99 \mathrm{~A}$ & $44,70 \pm 3,81 B$ \\
\hline Vértebras lombares 4-6 & $60,74 \pm 6,04 \mathrm{~A}$ & $34,96 \pm 3,22 \mathrm{C}$ & $56,02 \pm 3,78 \mathrm{~A}$ & $40,43 \pm 5,62 B$ \\
\hline
\end{tabular}

*Médias seguidas de mesma letra na linha não diferementre si $(p>0,05)$.
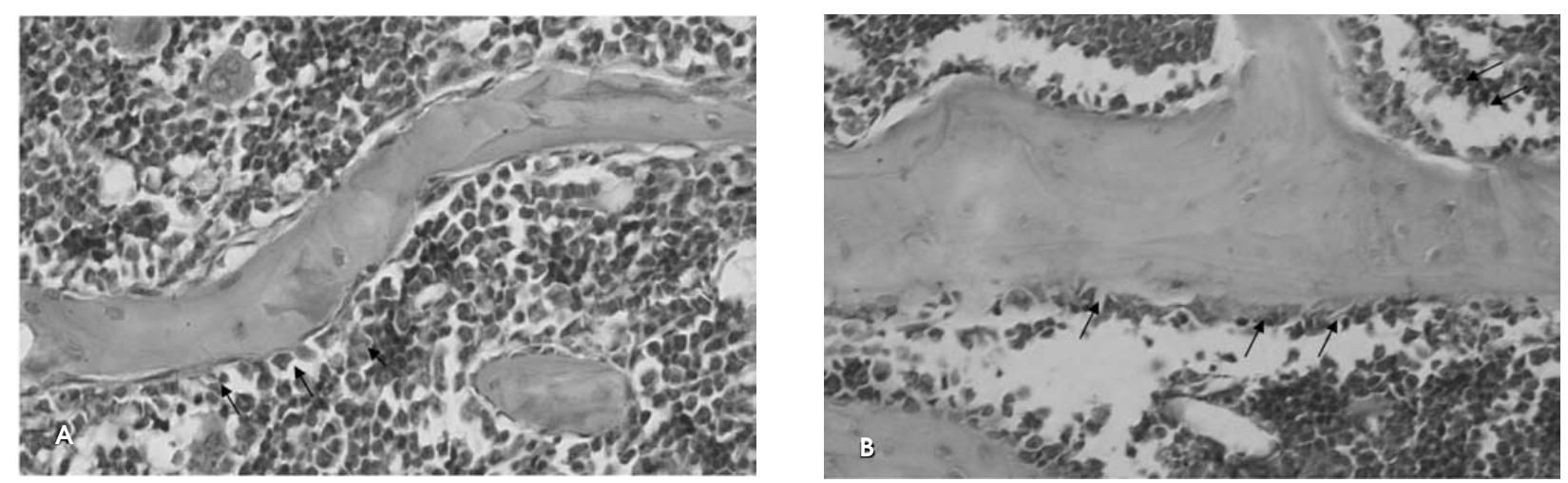

Figura 2. Vértebras torácicas 8-13 de ratas, HE, 286x. A) Grupo eutireóideo lactante com trabécula recoberta por osteoblastos fusiformes (setas); B) Grupo hipertireóideo lactante com trabéculas recobertas por osteoblastos cuboidais dispostos em duas ou mais camadas (setas). 
Nas vértebras, a porcentagem de tecido trabecular era significativamente maior, com a presença de trabéculas espessas e confluentes (Figura 1D) revestidas por osteoblastos cuboidais. Havia também vários focos de hiperplasia osteoblástica, ao contrário do grupo eutireóideo lactante que apresentava trabéculas com cobertura osteoblástica fusiforme (Figura 2). A cortical das vértebras também se apresentou espessa. No fềmur e na tíbia, o grau de osteopenia e suas características foram semelhantes a do grupo eutireóideo lactante. As trabéculas se encontravam em número reduzido, delgadas e fragmentadas. A maioria dos osteócitos era ativa, com núcleos grandes alojados em lacunas periosteocíticas alargadas. A cobertura osteoblástica era predominantemente constituída por células fusiformes. A cortical também se apresentou delgada e recoberta por periósteo pouco celularizado e delgado.

\section{DISCUSSÃo}

Os níveis plasmáticos de tiroxina foram mais elevados no grupo tratado com tiroxina, o que aliado aos sinais clínicos descritos comprova o estado hipertireóideo destes animais. A redução da dose de tiroxina realizada durante a gestação e a lactação foi realizada a fim de que não houvesse morte dos filhotes pela transferência de tiroxina por meio do leite, tal como relatado por Rosato e cols. (13). De fato, em todo o experimento não houve nenhuma morte de filhote (dados não demonstrados).

No grupo eutireóideo lactante, a osteopenia ocorreu por redução da atividade osteoblástica aliada ao aumento da reabsorção óssea por osteólise osteocítica. É provável que a redução do estrógeno durante a lactação seja um dos agentes etiológicos envolvidos na gênese da insuficiência osteoblástica, à semelhança do que é observado nas osteopenias pós-castração em ratas $(8,12)$ e pós-menopausa em mulheres (14). Já o aumento da reabsorção óssea provavelmente se deve à necessidade de transferência de cálcio para o feto que sabidamente é oriundo da ingestão de cálcio materno e da mobilização óssea (3).

Os estudos sobre a massa óssea de mulheres gestantes e lactantes são contraditórios, demonstrando osteopenia $(5,15)$ ou nenhuma anormalidade $(16,17)$. Acredita-se que essa disparidade de resultados deva-se a diferença na idade da população estudada, nos hábitos alimentares, no número de partos e de fetos nascidos e no período de aleitamento $(3,16)$.
Ratos produzem aproximadamente $70 \mathrm{ml}$ de leite/ dia com $30 \mathrm{mg} / \mathrm{ml}$ de cálcio. Estima-se que cada filhote reduz a densidade vertebral da mãe $\mathrm{em} 6,7 \mathrm{mg} / \mathrm{cm}^{2}$. Em mulheres, a perda de cálcio durante nove meses de lactação é maior que a perda durante a gestação. Aproximadamente 280 a $400 \mathrm{mg}$ de cálcio são eliminados diariamente no leite (3). Esta demanda do cálcio poderia ser compensada pelos mecanismos que incluem absorção intestinal aumentada de cálcio dietético, reabsorção renal do cálcio ou mobilização do mineral do esqueleto maternal. Entretanto, a hipercalciúria e a não reabsorção renal do cálcio implicam balanço sérico negativo de cálcio e osteopenia lactacional (16).

O hipertireoidismo, por si só, é uma causa importante de osteopenia em modelos animais (8) e na mulher (9). No entanto, no presente estudo, a tiroxina na dose e no período administrados não induziu a osteopenia. No hipertireoidismo, há estímulo tanto da aposição quanto da reabsorção ósseas (18), mas a diminuição da massa óssea advém da supremacia do processo catabólico diante do anabólico (19). Além disso, foi demonstrado que a osteopenia em ratas hipertireóideas varia de acordo com o indivíduo, com o sítio ósseo e com o tempo de administração da tiroxina (8).

As ratas hipertireóideas deste estudo tiveram número significativamente mais elevado de filhotes (11), o que poderia implicar piora da osteopenia lactacional, que é influenciada pelo número de filhotes (3). No entanto, o hipertireoidismo não agravou a osteopenia lactacional em nenhum dos sítios ósseos estudados. Nas vértebras, o hipertireoidismo minimizou a osteopenia lactacional, mas na tíbia e no fêmur a osteopenia manteve-se em grau semelhante ao do grupo eutireóideo lactante. É provável que o hipertireoidismo tenha minimizado a osteopenia lactacional por estimular a atividade osteoblástica, já que neste grupo houve, em vários sítios, hipertrofia e hiperplasia de osteoblastos, célula responsável pela síntese de matriz óssea (20). Mas sabese também que além de aumentar a atividade osteoblástica, o hipertireoidismo aumenta a reabsorção óssea, não havendo entre os sítios ósseos uniformidade de resposta ao hipertireoidismo (8), tal como observado na tíbia e no fêmur.

A tiroxina (T4) e a triiodotironina (T3) exercem profunda influência no metabolismo ósseo $(21,22)$ e na homeostasia do cálcio e do fósforo (23). A presença de receptores nucleares para o hormônio tireoidiano nos osteoblastos, nos osteócitos e nos osteoclastos (24) sugere que a ação dos hormônios tireoidianos sobre o osso é direta, embora eles possam agir indiretamente, já 
que estimulam a síntese de fatores de crescimento, citocinas e outros hormônios (25).

Assim, da mesma forma que os esteróides sexuais, T3 e T4, também estimulam a expressão de genes nos osteoblastos para a produção de colágeno, osteocalcina e fatores de crescimento semelhantes à insulina (IGFs), importantes para a síntese de matriz óssea $(26,27)$, os genes que codificam a síntese de receptores para IGF-1 e para proteínas ligantes de IGF são os principais alvos da ação dos hormônios tireoidianos nos osteoblastos, $\mathrm{O}$ que pode explicar, em parte, o efeito anabólico desses hormônios sobre o osso (28). Além do mais, há receptores para os hormônios tireoidianos nas células da medula óssea, precursoras da linhagem osteoblástica (29), fato esse que talvez explique o porquê da hiperplasia osteoblástica no osso de ratas hipertireóideas (8). Os hormônios tireoidianos também estimulam a síntese e a atividade da fosfatase alcalina, mediadora da síntese e da mineralização ósseas (30).

Vários são os relatos de que o hipertireoidismo, quando associado à menopausa, aumenta o risco para a osteoporose, pois potencializa a diminuição da massa óssea desencadeada pela deficiência dos esteróides sexuais $(9,10)$. Foi comprovado, no entanto, que a tiroxina, quando administrada em pequenas doses ou por curto período, reverte a osteoporose de ratas castradas, mas quando administrada em doses elevadas e por longo período intensifica a osteopenia (7) ou a torna mais extensa (8). Isso reafirma que o hipertireoidismo é fator de risco para a indução ou o agravamento da osteopenia da castração, pelo menos em algum momento da associação (8). Embora, no presente estudo o hipertireoidismo não tenha resultado piora da osteopenia lactacional em ratas, mais estudos são necessários em mulheres lactantes com hipertireoidismo após período lactacional prolongado e gestações sucessivas.

\section{CONCLUSÃO}

O hipertireoidismo não agrava a osteopenia lactacional em ratas, mas minimiza a osteopenia vertebral por aumentar a atividade osteoblástica.

\section{REFERÊNCIAS}

1. Liu-Seifert $\mathrm{H}$, Kinon BJ, Ahi J, Lamberson S. Osteopenia associated with increased prolactin and aging in psychiatric patients treated with prolactin-elevating antipsychotics. Ann N Y Acad Sci. 2004;1032:297-8.
2. Howes OD, Wheeler MJ, Meaney AM, O'Keane V, Fogelman I, Blake $\mathrm{G}$, et al. Bone mineral density and its relationship to prolactin levels in patients taking antipsychotic treatment. J Clin Psychopharmacol 2005;25:259-61

3. Bowman BM, Miller SC. Skeletal adaptations during mammalian reproduction. J Musculoskelet Neuronal Interact. 2001;1:347-55.

4. Sowers M. Pregnancy and lactation as risk factors for subsequent bone loss and osteoporosis. J Bone Miner Res. 1996;11:1052-60.

5. Gambacciani M, Spinetti A, Gallo R, Cappagli B, Teti GC, Facchini V. Ultrasonographic bone characteristics during normal pregnancy: longitudinal and cross-sectional evaluation. Am J Obstet Gynecol. 1995;173:890-3.

6. Miller SC, Bowman BM. Comparison of bone loss during normal lactation with estrogen deficiency osteopenia and immobilization osteopenia in the rat. Anat Rec. 1998;251:265-74

7. Gouveia CHA, Jorgetti V, Bianco AC. Effects of thyroid hormone administration and estrogen deficiency on bone mass of female rats. J Bone Miner Res. 1997;12:2098-107.

8. Serakides R, Nunes VA, Ocarino NM, Nascimento EF. Efeito da associação hipertireoidismo-castração no osso de ratas adultas. Arq Bras Endocrinol Metab. 2004;48:875-84.

9. Fallon MD, Perry HM 3rd, Bergfeld M, Droke D, Teitelbaum SL, Avioli LV. Exogenous hyperthyroidism with osteoporosis. Arch Intern Med. 1983;143:442-4.

10. Campos-Pastor MM, Muñoz-Torres M, Escobar-Jiménez F, Ruiz de Almodovar M, Jodar Gimeno E. Bone mass in females with different thyroid disorders: influence of menopausal status. Bone Miner. 1993;21:1-8.

11. Freitas ES, Leite ED, Souza CA, Ocarino NM, Ferreira E, Cassali GD, et al. Histomorphometry and expression of Cdc47 and caspase- 3 in hyperthyroid rat uteri and placentas during gestation and postpartum associated with fetal development. Reprod Fertil Dev. 2007;19:498-509.

12. Ocarino NM, Marubayashi U, Cardoso TGS, Guimarães CV, Silva AE, Tôrres RCS, et al. Physical activity in osteoporosis treatment restore the mass of bones submitted or not to mechanical impact. J Musculoskelet Neuronal Interact. 2007;7:84-93.

13. Rosato RR, Jiménez MS, Jahn GA. Effects of chronic thyroid hormone administration on pregnancy, lactogenesis and lactation in the rat. Acta Endocrinol. 1992;127:547-54.

14. Raisz LG. Pathogenesis of osteoporosis: concepts, conflicts, and prospects. J Clin Invest. 2005;111:3318-25.

15. Kolthoff N, Eiken P, Kristensen B, Nielsen SP. Bone mineral changes during pregnancy and lactation: a longitudinal cohort study. Clin Sci (Lond). 1998;94:405-12.

16. Sowers MF, Scholl T, Harris L, Jannausch M. Bone loss in adolescent and adult pregnant women. Obstet Gynecol. 2000;96:189-93.

17. Henderson PH, Sowers M, Kutzko KE, Jannausch ML. Bone mineral density in grand multiparous women and extended lactation. Am J Obstet Gynecol. 2000;182:1371-7.

18. Huang BK, Golden LA, Tarjan G, Madison LD, Stern PH. Insulin-like growth factor I production is essential for anabolic effects of thyroid hormone in osteoblasts. J Bone Miner Res. 2000;15:188-97.

19. Huang BK, Golden LA, Tarjan G, Madison LD, Stern PH. Insulin-like growth factor I production is essential for anabolic effects of thyroid hormone in osteoblasts. J Bone Miner Res. 2000;15:188-97. 
20. Mackie EJ. Osteoblasts: novel roles in orchestration of skeletal architecture. Int J Biochem Cell Biol. 2003;35:1301-5.

21. Burkhart JM, Jowsey J. Parathyroid and thyroid hormones in the development of immobilization osteoporosis. Endocrinology. 1967;81:1053-62.

22. Pepene CE, Kasperk CH, Pfeilschifter J, Bórccsók I, Gozariu L, Ziegler $\mathrm{R}$, et al. Effects of triiodothyronine on the insulin-like growth factor system in primary human osteoblastic cells in vitro. Bone. 2001;29:540-6.

23. Serakides R, Nunes VA, Nascimento EF, Silva CM, Ribeiro AFC. Relação tireóide-gônadas e níveis plasmáticos de fósforo, cálcio e fosfatase alcalina em ratas. Arq Bras Med Vet Zoot 2000;52:579-85.

24. Abu EO, Bord S, Horner A, Chatterjee VK, Compston JE. The expression of thyroid hormone receptors in human bone. Bone 1997;21:137-42.

25. Kim CH, Kim HK, Shonk YK, Lee KU, Kim GS. Thyroid hormones stimulate basal and interleukin (IL)1 induced IL-6 production in human bone marrow stromal cells: a possible mediator of thyroid hormone-induced bone loss. J Endocrinol. 1999;160:97-102.

26. Bilezikian JP, Raizs LG, Rodan GA. Principles of bone biology. San Diego: Academic Press; 1996.

27. Bland R. Steroid hormone receptor expression and action in bone. Clin Sci (Lond). 2000;98:217-40.
28. Pepene CE, Kasperk CH, Pfeilschifter J, Borcsok I, Gozariu L, Ziegler $\mathrm{R}$, et al. Effects of triiodothyronine on the insulin-like growth factor system in primary human osteoblastic cells in vitro. Bone. 2001;29:540-6.

29. Siddiqi A, Parsons MP, Lewis JL, Monson JP, Williams GR, Burrin JM. TR expression and function in human bone marrow stromal and osteoblast-like cells. J Clin Endocrinol Metab. 2002;87:906-14

30. Banovac K, Koren E. Triiodothyronine stimulates the release of membrane-bound alkaline phosphatase in osteoblastic cells. Calcif Tissue Int. 2000;67:460-5.

Endereço para correspondência:

\section{Rogéria Serakides}

Setor de Patologia do Departamento de Clínica e Cirurgia Veterinárias da UFMG

Av. Pres. Antônio Carlos, 6.627 Caixa Postal 567

31.270-901 Belo Horizonte, MG

E-mail: serakide@dedalus.lcc.ufmg.br 